\title{
Exploration into the Clinical Value of Breast-Conserving Therapy Combined with Sentinel Lymph Node Biopsy in the Treatment of Early Breast Cancer
}

\begin{abstract}
FANG FANG AND LIN GU ${ }^{1 *}$
National Clinical Research Center for Cancer, Key Laboratory of Cancer Prevention and Therapy of Tianjin, Tianjin Clinical Research Center for Cancer, ${ }^{1}$ National Clinical Research Center for Cancer, Key Laboratory of Cancer Prevention and Therapy of Tianjin, Tianjin Clinical Research Center for Cancer, Key Laboratory of Breast Cancer Prevention and Therapy (Ministry of Education), The Second Department of Breast oncology, Tianjin Medical University Cancer Institute and Hospital, Tianjin 300060, China
\end{abstract}

Fang et al.: Breast-Conserving Therapy Combined with Sentinel Lymph Node Biopsy

\begin{abstract}
To observe and analyze the application effect of breast-conserving therapy combined with sentinel lymph node biopsy in the treatment of early breast cancer. We selected 120 patients with early breast cancer who were treated in our hospital as subjects. Immediately thereafter, the patients were divided into study group and reference group, each with 60 cases. Different treatment plans were performed. The reference group was treated with conventional surgical mastectomy and axillary lymph node dissection. The study group was treated with breast-conserving therapy combined with sentinel lymph node biopsy. The treatment results of the two groups were observed and compared. By observing intraoperative operative time and intraoperative blood loss of the two groups, the results showed the two were significantly less in the study group than the reference group, $\mathbf{p}<\mathbf{0 . 0 5}$. In comparison of the patients postoperative quality of life and breast cosmetic results, the study group was obviously superior to the reference group, $p<0.05$. In addition, comparison of postoperative local recurrence rate and distant metastasis rate revealed no significant difference and there was no statistical significance, $p>0.05$. Treatment of early breast cancer patients with breast-conserving therapy combined with sentinel lymph node biopsy can achieve relatively good results and can significantly improve patient's quality of life.
\end{abstract}

Key words: Breast-conserving therapy combined with sentinel lymph node biopsy, early breast cancer, clinical value

People's living standards are constantly improving, living habits and dietary structures are changing. Coupled with the destruction of the surrounding environment, the reduction of air quality, the acceleration of the pace of work, the impact of family factors, etc., the incidence of breast cancer shows an increasingly upward trend. Breast cancer is a malignant tumor that can have a serious impact on the normal life and work of female patients. Failure to receive timely and effective treatment can endanger the lives of patients ${ }^{[1-3]}$.

Breast cancer is a malignant tumor that occurs in the glandular epithelium of the breast (fig. 1). The $99 \%$ of breast cancer occurs in the female population. Breast cancer cells lose the characteristics of normal cells. The cells have loose connections and are easy to fall off ${ }^{4]}$.

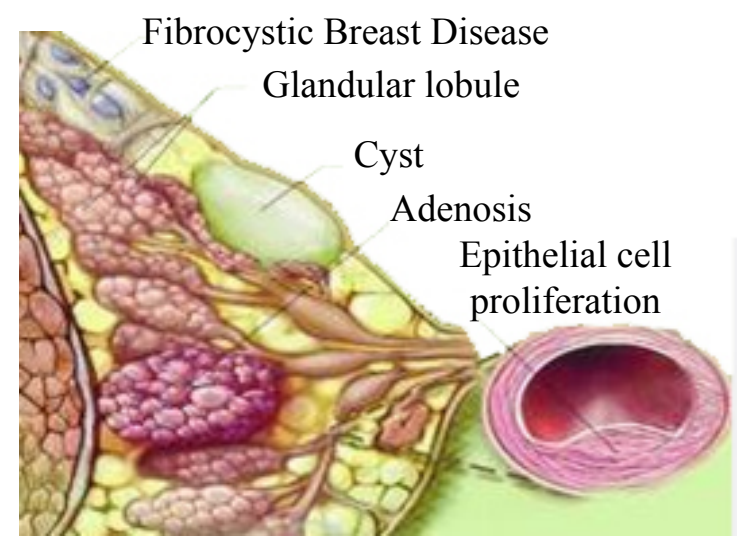

Fig. 1: Breast cancer

Once cancer cells (fig. 2) fall off, free cancer cells can spread throughout the body along with blood or lymph fluid, forming metastases that endangers life. Breast 
cancer has become a common tumor that threatens the physical and mental health of women. It has become a major public health problem in current society. This study is to observe and analyze the clinical application value of breast-conserving therapy combined with sentinel lymph node biopsy in the treatment of early breast cancer.

\section{MATERIALS AND METHODS}

\section{General Information:}

We studied 120 patients with early breast cancer who were treated in our hospital. All patients were diagnosed with breast cancer by preoperative puncture or intraoperative rapid pathology. The time range was from June 2014 to December 2017. The patients inclusion criteria meet the following aspects: breast tumors are $3 \mathrm{~cm}$ or less in diameter, single tumors, margins are more than $2 \mathrm{~cm}$ from the areola margin and the type of cases are invasive breast cancer (fig. 3), At the same time, the results of clinical examination showed that there was no regional lymph node and distant organ metastasis and the patient had breast conserving appeal. Exclusion criteria were: ipsilateral axillary examination

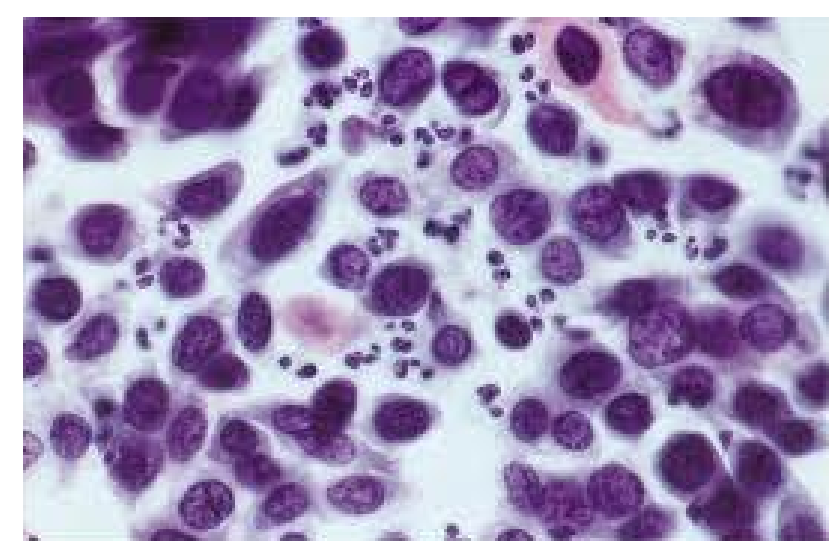

Fig. 2: Cancer cells

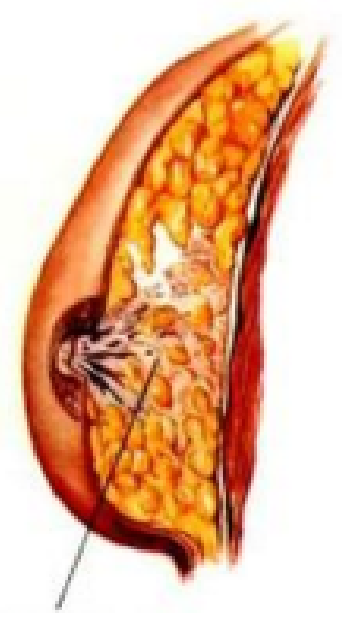

Fig. 3: Invasive breast cancer and imaging findings revealed enlarged lymph nodes, mental disorders and unwillingness to join the study.

The patients were divided into study group and reference group, each with 60 cases. Patients in the study group ranged in age from 32 to $58 \mathrm{y}$ and average $(45.7 \pm 3.2)$ $\mathrm{y}$; patients in the reference group ranged in age from 34 to $56 \mathrm{y}$ and average $(46.8 \pm 3.5) \mathrm{y}$. Comparison of the patients relevant data showed comparability, $p>0.05$.

\section{Methods:}

Treatment methods for the reference group: The reference group was implemented with a modified radical surgery plan with musculus pectoralis major and minor retained, i.e., conventional total mastectomy plus ipsilateral axillary lymph node dissection. Strict dissection was performed for all lymph nodes from the latissimus dorsi front edge to the medial border of musculus pectoralis minor.

Treatment methods for the study group: After anesthesia was performed, $2 \mathrm{ml}$ of methylene blue injection (1\%) was injected into the subcutaneous tissue of the affected areola area. After $20 \mathrm{~min}$, a radial incision or a curved incision was performed to remove the tumor in accordance with the patient's specific tumor site, the surrounding $2 \mathrm{~cm}$ normal glandular tissue was resected and the incisal margin was subjected to frozen section pathological examination. If the result of the examination is negative, breast-conserving surgery is implemented. If the result is positive on both occasions, a full mastectomy is performed. Sentinel lymph node biopsy is performed by incisions in the upper part of the plica of the breast and axilla, routine incision of the skin and subcutaneous tissue and flap separation. The first blue-stained lymph node, the sentinel lymph node, into which the lymphatic vessel entered, was found. The enlarged hard-lymph nodes found in the palpation of axilla area were sent for rapid pathological examination. If the result is negative, close the incision. If the result is positive, continue to perform axillary lymph node dissection.

\section{Observation indicators:}

We observed and counted the patient's operative time, intraoperative blood loss, postoperative quality of life, postoperative local recurrence rate and distant metastasis rate and breast cosmetic results.

\section{Statistical methods:}

The statistical analysis software used was SPSS 21.0, where the measurement data were expressed as 
mean \pm average $(\overline{\mathrm{x}} \pm \mathrm{s})$ and $\mathrm{t}$ was used for comparison between groups. The count data was expressed using natural numbers (n) and percentages (\%) and $\mathrm{x}^{2}$ was used for comparison between groups. When $\mathrm{p}<0.05$, it is of statistical value.

\section{RESULTS AND DISCUSSION}

As shown in Table 1 below, by observing and comparing the operative time and intraoperative blood loss between the study group and the reference group, the results show that the study group has shorter operative time and less blood loss than the reference group, $p<0.05$, with statistical significance.

As shown in Table 2 below, by observing and comparing the quality of life of patients after treatment, the results show that the scoring is significantly higher in the study group than the reference group in all aspects, $\mathrm{p}<0.05$, statistically significant.

As shown in Table 3 below, 1 y follow-up is performed after surgery. After observation of local recurrence and metastasis, the results show no significant differences

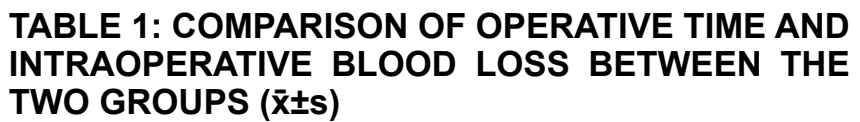
TWO GROUPS ( $\overline{\mathbf{x}} \pm \mathbf{s})$

\begin{tabular}{lccc}
\hline Group & $\begin{array}{c}\text { Case } \\
\text { number }\end{array}$ & $\begin{array}{c}\text { Operative time } \\
(\min )\end{array}$ & $\begin{array}{c}\text { Intraoperative } \\
\text { blood loss }(\mathrm{ml})\end{array}$ \\
\hline $\begin{array}{l}\text { Study group } \\
\text { Reference }\end{array}$ & 60 & $60.23 \pm 13.50$ & $52.09 \pm 11.28$ \\
group & 60 & $92.08 \pm 16.74$ & $143.68 \pm 10.29$ \\
$\mathrm{t}$ & & 10.28 & 11.40 \\
$\mathrm{p}$ & & $<0.05$ & $<0.05$ \\
\hline
\end{tabular}

between the groups, $\mathrm{p}>0.05$ and there was no statistical significance.

As shown in Table 4 below, 1 y after surgery, evaluation is made according to joint center for radiation therapy (JCRT) criteria. Compared with the reference group, the study group has better breast cosmetic results, $p<0.05$, statistically significant.

Under breast cancer, breast gland epithelial cells have undergone gene mutation under the action of a variety of carcinogenic factors, resulting in uncontrolled cell proliferation. The metastasis in vital organs such as lung metastases, brain metastases, bone metastases, etc. will directly threaten human life. Therefore, breast cancer is a malignant tumor that seriously jeopardizes human life ${ }^{[4,5]}$. With the continuous improvement of medical technology, breast-conserving surgery has achieved rapid development. It has the advantages of fewer traumas, promoted postoperative rehabilitation and retention of breast. It has important applications in the treatment of breast cancer patients and effectively reduces the patient's psychological stress and improves their quality of life ${ }^{[6,7]}$. During the application of such surgical treatment, one problem that needs attention is that it has a significant indication and the best surgical technique should be selected by strictly following the patient's actual condition. Sentinel lymph node (fig. 4) is the first station in the drainage pathway of breast cancer to axillary lymph node. Sentinel lymph node biopsy is a measure that can highly detect axillary lymph node metastasis and has been widely used.

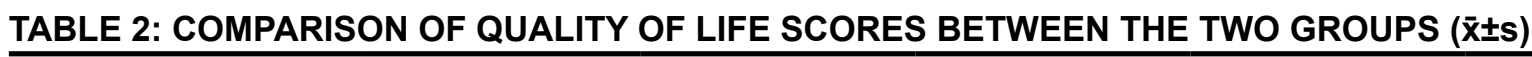

\begin{tabular}{lccccc}
\hline Group & Time & Social function & Body function & Mental function & Vital function \\
\hline Study group $(\mathrm{n}=60)$ & Before operation & $13.0 \pm 0.53$ & $13.2 \pm 0.63$ & $14.6 \pm 0.69$ & $14.0 \pm 0.52$ \\
& After operation & $23.9 \pm 0.68$ & $23.4 \pm 0.75$ & $20.6 \pm 0.73$ & $21.6 \pm 0.78$ \\
Reference group $(\mathrm{n}=60)$ & Before operation & $13.2 \pm 0.40$ & $13.7 \pm 0.64$ & $14.2 \pm 0.75$ & $14.1 \pm 0.82$ \\
& After operation & $16.7 \pm 0.52$ & $16.9 \pm 0.53$ & $17.6 \pm 0.48$ & $18.5 \pm 0.91$ \\
\hline
\end{tabular}

TABLE 3: LOCAL RECURRENCE AND METASTASIS IN THE TWO GROUPS [n (\%)]

\begin{tabular}{lccc}
\hline Group & Case number & Recurrence rate & Metastasis rate \\
\hline Study group & 60 & $2(3.33)$ & $2(3.33)$ \\
Reference group & 60 & $3(5.00)$ & $2(3.33)$ \\
$x^{2}$ & & 1.20 & 0.00 \\
$p$ & & $>0.05$ & $>0.05$ \\
\hline
\end{tabular}

TABLE 4: BREAST COSMETIC EFFECT OF THE TWO GROUPS [n (\%)]

\begin{tabular}{lccccc}
\hline Group & Case number & Fine & Ordinary & Poor & Overall satisfaction \\
\hline Study group & 60 & 30 & 26 & 4 & $56(93.33)$ \\
Reference group & 60 & 15 & 15 & 30 & $30(50.00)$ \\
$\mathrm{x}^{2}$ & & & & & 14.02 \\
$\mathrm{p}$ & & & & & 0.05 \\
\hline
\end{tabular}




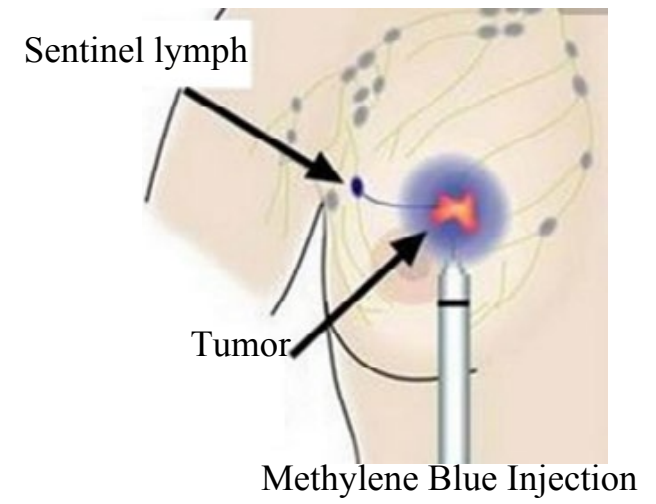

Fig. 4: Sentinel lymph node

Sentinel lymph node biopsy is different from the traditional form of axillary lymph node dissection, which can prevent the damage of the vascular nerves and lymphatics of the axillary fossa and avoid postoperative upper limb edema, dysfunction and sensory abnormalities of the skin inside the forearm, thereby improving safety and reliability of the patient's treatment. The application of breast-conserving therapy combined with sentinel lymph node biopsy in early breast cancer patients can improve the efficacy of breast cancer and help patients achieve a higher quality of life. It is currently the preferred surgical treatment for early breast cancer in Western countries ${ }^{[8-11]}$. The results of this study show that, by observing and comparing operative time and intraoperative blood loss between the study group and the reference group, the study group had shorter operative time and less intraoperative blood loss, $p<0.05$, with statistical significance. In comparison of quality of life of the patients after treatment, the results showed that scoring of study group was significantly superior to the reference group in all aspects, $p<0.05$, statistically significant. In evaluation according to JCRT criteria, the breast cosmetic results were better in the study group than the reference group, $\mathrm{p}<0.05$, statistically significant. In postoperative $1 \mathrm{y}$ follow up, after observation of the patients local recurrence and metastasis, the results showed no significant difference between the two groups ( $p>0.05$ ), not statistically significant. It has demonstrated that the application of breast-conserving therapy combined with sentinel lymph node biopsy can achieve relatively satisfactory results in the treatment of early breast cancer.

To sum up, application of breast-conserving therapy combined with sentinel lymph node biopsy can achieve relatively good results in the treatment of early breast cancer patients. Featuring short operation time, small trauma, it can significantly improve patient's quality of life and achieve good cosmetic results. Therefore, it enjoys huge application value.

\section{Conflicts of Interest:}

The authors declared no conflict of interest.

\section{REFERENCES}

1. Peng Z, Xu GY, Wang CQ, Zhou ZJ. The clinical value of explosive breast combined with sentinel lymph node biopsy in the treatment of 50 cases of early breast cancer. Matern Child Health Care China 2014;29(35):5935-7.

2. Liu XY, Li Z, Zhang HJ, Li MH. The clinical value of explosive breast combined with sentinel lymph node biopsy in the treatment of early breast cancer. Hebei Med J 2014;36(6):8378 .

3. Zhou Q. Comparison of effects of breast-conserving surgery and modified radical operation in the treatment of early breast cancer. China Med Her 2015;12(32):100-3.

4. Kiderlen M, Bastiaannet E, Walsh PM, Keating NL, Schrodi S, Engel J, et al. Surgical treatment of early stage breast cancer in elderly: an international comparison. Breast Cancer Res Treat 2012;132(2):675-82.

5. Van Vlaenderen I, Canon JL, Cocquyt V, Jerusalem G, Machiels JP, Neven P, et al. Trastuzumab treatment of early stage breast cancer is cost-effective from the perspective of the Belgian health care authorities. Acta Clin Belg 2009;64(2):100-12.

6. Guo F. Observation of clinical value of breast-conserving therapy combined with sentinel lymph node biopsy in the treatment of early breast cancer. World Latest Med Inform 2015;15(90):1-2.

7. Lv XD. Analysis of clinical value of sentinel lymph node dissection in the treatment of early breast cancer. Contemp Med 2016;22(31):23-4.

8. Aydiner A, Tas F. Meta-analysis of trials comparing anastrozole and tamoxifen for adjuvant treatment of postmenopausal women with early breast cancer. Trials 2008;9(1):1-9.

9. Ban M, Viculin J, Tomic S, Capkun V, Strikic A, Mise BP, et al. Retrospective analysis of efficacy of trastuzumab in adjuvant treatment of HER 2 positive early breast cancer-single institution experience. Neoplasma 2016;63(5):761-7.

10. Dahaba AA, Grabner T, Rehak PH, List WF, Metzler H. Remifentanil versus morphine analgesia and sedation for mechanically ventilated critically ill patients: a randomized double blind study. Anesthesiology 2004;101(3):640-6.

11. Early Breast Cancer Trialists' Collaborative Group. Effects of chemotherapy and hormonal therapy for early breast cancer on recurrence and 15-year survival: an overview of the randomised trials. Lancet 2005;365:1687-717.

This is an open access article distributed under the terms of the Creative Commons Attribution-NonCommercial-ShareAlike 3.0 License, which allows others to remix, tweak, and build upon the work non-commercially, as long as the author is credited and the new creations are licensed under the identical terms

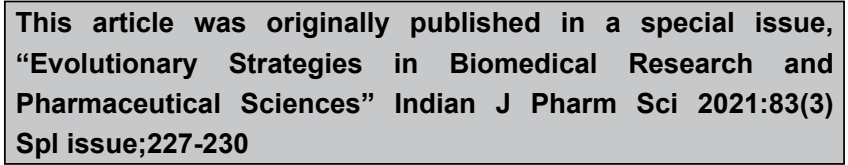

